\title{
MVLIBRAS: ambiente digital para comunidades de aprendizagem com recursos inclusivos para surdos
}

\author{
Luiz Fernando Reinoso ${ }^{1}$, Orivaldo de Lira Tavares ${ }^{1}$ \\ ${ }^{1}$ Departamento de Informática - Universidade Federal do Espírito Santo (UFES) \\ Av. Fernando Ferrari, 514, Goiabeiras - 29.075-910 - Vitória - ES - Brasil \\ themedievais@gmail.com, tavares@inf.ufes.br
}

\begin{abstract}
This article describes a digital architecture for learning LIBRAS (Brazilian Sign Language) and Portuguese. The MVLIBRAS is a digital environment for collaborative learning, where teachers, interpreters and deaf students and listeners can learn the Brazilian Sign Language and Portuguese, in a interactive and inclusive way. This paper discusses the use of translators and assistive technologies in learning and presents aspects of the development, use and validation of MVLIBRAS. It also introduces a pedagogical architecture that uses resources of the MVLIBRAS for teaching and learning of words of the brazilian Portuguese and their translations for LIBRAS.
\end{abstract}

Resumo. Este artigo descreve uma arquitetura digital para a aprendizagem de LIBRAS (Linguagem Brasileira de Sinais) e de Português. O MVLIBRAS é um ambiente digital de aprendizagem colaborativa, onde professores, intérpretes e alunos surdos e ouvintes podem aprender a língua de sinais brasileira e a língua portuguesa, de modo interativo e inclusivo. Este artigo aborda o uso de tradutores e tecnologias assistivas na aprendizagem e apresenta aspectos do desenvolvimento, uso e validação do MVLIBRAS. Também apresenta uma arquitetura pedagógica que usa recursos do MVLIBRAS para o ensino e aprendizagem de palavras do Português e suas traduções para LIBRAS.

\section{Introdução}

No processo de ensino-aprendizagem de LIBRAS as Tecnologias de Informação e Comunicação (TICs) vêm sendo empregadas como um grande recurso de inclusão de pessoas surdas nas comunidades de aprendizagem, criando meios para surdos e ouvintes terem acesso fácil à informação e comunicação.

\subsection{Objetivos}

Este artigo visa apresentar tecnologias de suporte à aprendizagem e acessibilidade para pessoas surdas. Tais tecnologias são incluídas no MVLIBRAS, um ADA (Ambiente Digital de Aprendizagem) que integra recursos de tecnologias assistivas para suporte à aprendizagem de LIBRAS e Português. O MVLIBRAS pode ser usado por aprendizes surdos e ouvintes de modo colaborativo.

É apresentado os requisitos funcionais do MVLIBRAS e uma arquitetura pedagógica para o qual os recursos do ADA são especialmente implementados e 
pesquisas descritivas, que trazem levantamento de padrões de comportamento dos professores, intérpretes e alunos, envolvidos no ensino e aprendizagem de LIBRAS.

\subsection{Justificativa}

A LIBRAS não é apenas uma simples gesticulação da língua Portuguesa, é uma língua distinta, que parte de referencial visual/espacial, possuindo gramática própria. A representação básica da Libras é baseada em cinco parâmetros: ponto de articulação, configuração de mão, orientação, expressão facial e corporal [Farjado et al. 2015]. A LIBRAS é uma língua oficial brasileira, validada pela lei $\mathrm{n}^{\circ} 10.436$, de 24 de abril de 2002 [Brasil 2002].

Assim, faz-se necessário o uso de abordagens pedagógicas apropriadas para motivar os estudantes surdos e os professores deles a aprenderem LIBRAS. Existem assuntos na aprendizagem de LIBRAS que são melhor aprendidos quando se dispõe de recursos digitais apropriados. Neste artigo que trata da aprendizagem de palavras do Português e da tradução delas para a forma gesticulada animada em LIBRAS, são apresentados recursos digitais importantes para potencializarem essa aprendizagem.

Este artigo surgiu com a proposta de desenvolver e implantar um ADA para ensino e aprendizagem de LIBRAS, valorizando a comunicação bilíngue entre aprendizes surdos e ouvintes, professores e intérpretes, garantindo recursos de inclusão e desenvolvimento colaborativo de atividades.

\subsection{Contextualização do problema}

Segundo dados da Secretaria Nacional de Promoção dos Direitos da pessoa com Deficiência, da população residente no país em 2010, 23,9\% cerca de 45.606.048 brasileiros têm algum tipo de deficiência visual, auditiva, motora, mental ou intelectual, sendo deste total 7,6\% (cerca de 346.606) totalmente surdas [Brasil 2012]. Estima-se que $60 \%$ conhecem a Língua Brasileira de Sinais (LIBRAS), mas a comunicação com ouvintes é difícil [Coradine et al. 2004].

A aprendizagem do aluno surdo envolve um intérprete. O intérprete é o profissional que domina a língua de sinais e a língua falada do país e é qualificado para desempenhar a função de intérprete [Brasil 2004]. A Lei $\mathrm{n}^{\circ} 12.319$, de $1^{\circ}$ de setembro de 2010, dá reconhecimento legal a profissão de tradutor e intérprete de LIBRAS [Brasil 2010].

O envolvimento dos alunos com professores e intérpretes na aprendizagem da LIBRAS e da linguagem escrita, bem como da leitura e interpretação textual exigem muita energia e tempo, o que pode prejudicar outras áreas de estudo [Bistol et al. 2010]. Por isso, é importante o uso das TICs que contribuam para facilitar a aprendizagem de LIBRAS por parte dos docentes e discentes de uma entidade de ensino.

\subsection{Metodologia}

Este artigo foi baseado em análises de trabalhos de diversos autores da área de Informática na Educação, sobre Arquiteturas Pedagógicas, uso de tradutores na aprendizagem e tecnologias assistivas, tendo como foco principal a acessibilidade para deficientes auditivos. Para conhecer o público alvo desta pesquisa, foi usada a 
metodologia de pesquisa descritiva, onde são descritas características, propriedades e relações existentes na comunidade pesquisada. Assim, foi feito o acompanhamento das atividades de profissionais da área de educação especial, para se levantar os recursos digitais úteis para agilizar essas atividades. Entre essas atividades, destaca-se a prática de criação textual entre surdos e ouvintes de modo manual, em grupo. Durante a criação dos textos é realizada a tradução de textos em Português escrito para LIBRAS gesticulada, o que permite a aprendizagem do Português e de LIBRAS.

O restante deste artigo está organizado da seguinte forma: na Seção 2 abordamos as TICs e seu uso como ferramentas inclusivas, na Seção 3, uma introdução as Arquiteturas Pedagógicas (AP) e a referente proposta de AP deste trabalho, a APLP. Na Seção 4, é apresentado o sistema MVLIBRAS, criado para atender a AP proposta, a Seção 5, traz a avaliação do sistema. Na Seção 6 teremos as considerações finais.

\section{As TICs como veiculo de aprendizagem e inclusão para surdos}

O desenvolvimento de ambientes de suporte a comunicação e aprendizagem de surdos vem sendo tema de pesquisas a algum tempo com projetos como o gaW, graW-S e JavaS (Java Surdos). Esses ambientes usam LIBRAS e Português, como linguagens de comunicação para surdos e ouvintes, respectivamente, além da tradução bi-direcional entre emissor e receptor [Costa et al. 2004].

A maioria dos tradutores digitais de Português para LIBRAS usam uma memória de tradução, baseado em pares de expressões, onde uma palavra tem sua tradução com um vídeo gesticulado do sinal, assim representam expressões LIBRAS na forma gestual animada, tal como fazem no projeto Falibras [Coradine et al. 2004], SOTAC [Breda 2009], Sign WebMessage [Souza e Pinto 2003 2004] e Sign WebForum [Rossi, Souza e Pinto 2004]. Sistemas mais atuais funcionam até mesmo em plataformas móveis, como o HandTalk [Santarosa et al. 2014] que utiliza avatar virtual e traduz áudio e texto escrito, além de permitir a tradução de sites.

Ambientes virtuais de aprendizagem com recursos digitais como os apresentados estão gradativamente sendo inseridos nas instituições educacionais. Na educação a distância está cada vez mais comum se encontrar esses recursos digitais [Bispo e Saretto 2015].

\section{Arquiteturas Pedagógicas}

Com a concepção de novas tecnologias da informação e com o crescimento das redes de computadores, a cada dia se estudam novas formas de se educar para a autonomia e a cooperação. Neste sentido Carvalho et al. (2005), propõe a definição de arquiteturas pedagógicas (AP), descritas como suportes estruturantes para a aprendizagem. Para tanto utilizam de diferentes componentes tais como: abordagem pedagógica, software livre, internet, inteligência artificial, educação a distância, concepção de tempo e espaço. Tais arquiteturas pedagógicas visam a aprendizagem com pensamento construtivista, ou seja, a partir de vivencias, experiências, reflexões e meta reflexões. Tendo como base o construtivismo de Jean Piaget e os conceitos da obra de Paulo Freire, Pedagogia para a Autonomia [Carvalho, Nevado e Menezes 2005]. 
Neste artigo definiremos uma Arquitetura Pedagógica como estrutura de aprendizagem constituída de: 1 . objetivo pedagógico; 2 . atividades pedagógicas; 3. metodologia; 4. recursos digitais.

O objetivo pedagógico define o resultado esperado da aplicação de uma AP. As atividades pedagógicas são aquelas elaboradas pelo professor, juntamente com o grupo de aprendizes, visando atingir o objetivo pedagógico.

A metodologia define como as atividades pedagógicas são desenvolvidas para se alcançar os objetivos. Os recursos digitais são aqueles escolhidos para viabilizarem ou agilizarem a execução das atividades pedagógicas.

A seguir, apresentamos uma arquitetura pedagógica usada como referência para a identificação dos requisitos do MVLIBRAS, ou seja, para definirmos esses requisitos precisamos identificar as reais necessidades da comunidade de aprendizagem.

\subsection{APLP - Arquitetura pedagógica para aprendizagem de palavras da LIBRAS e do Português}

Neste artigo usamos uma arquitetura pedagógica definida nas seções seguintes para promover a aprendizagem de palavras do Português e suas traduções para LIBRAS (APLP), por uma comunidade de surdos e ouvintes.

\subsubsection{Objetivo pedagógico}

O objetivo pedagógico a ser considerado é a aprendizagem de palavras LIBRAS, em sua forma gestual, a partir das correspondentes palavras do Português, em sua forma escrita, em atividades colaborativas entre aprendizes surdos e ouvintes.

\subsubsection{Atividades Pedagógicas}

Para atingir o objetivo pedagógico, são planejadas duas atividades pedagógicas: 1) edição de palavras escritas em Português e 2) tradução das palavras do Português para LIBRAS, em sua forma gestual.

\subsubsection{Metodologia}

Os temas das palavras a serem usadas nas atividades definidas são escolhidos pelo grupo de aprendizes, com a mediação do professor. Todas as atividades são desenvolvidas em grupos de 2 estudantes, de modo colaborativo, de modo a manter os estudantes motivados a aprenderem. Os grupos de aprendizes usam recursos digitais para a edição das palavras do Português e para a tradução delas para LIBRAS, bem como, para a definição pelos estudantes de novas palavras LIBRAS, que não estejam disponíveis ao tradutor de palavras.

A edição de um texto de modo colaborativo, de acordo com Souza et al. (2013) e Pimentel e Fuks (2012), deve enfatizar as ideias, opiniões e inferências de todos os autores, resultando em uma composição coletiva dos alunos surdos ou ouvintes, de modo que todos possam criar e rever os textos escritos. No caso desta arquitetura, é usada a edição de palavras. 


\subsubsection{Recursos digitais}

São usados recursos digitais, especialmente desenvolvidos pelos autores para a edição colaborativa de palavras, bem como tradutores de palavras e expressões do Português escrito para LIBRAS, além de um editor para os estudantes informarem novas palavras LIBRAS. Esses recursos foram, posteriormente, integrados na arquitetura do MVLIBRAS apresentada na seção posterior.

\section{O Sistema MVLIBRAS}

O MVLIBRAS é um ambiente digital para aprendizagem colaborativa de Português e LIBRAS, para que pessoas surdas e ouvintes possam aprender ambas línguas, a partir da interpretação colaborativa de textos escritos em Português e da tradução deles para LIBRAS, na forma gestual animada.

O MVLIBRAS também permite a construção individual de um dicionário de gestos visio-espaciais e palavras LIBRAS, e a construção pelos intérpretes autorizados de dicionários de grupo. Esse recurso pode ser usado para registrar sinais usados pelos aprendizes, de modo a permitir o acompanhamento da evolução da aprendizagem deles no uso da linguagem de sinais brasileira, bem como permitir o registro de expressões locais ou regionais em um dicionário comum para um grupo de pessoas.

O MVLIBRAS utiliza diversos dicionários de vídeos de palavras da LIBRAS, na forma gestual animada, durante as traduções. O uso desses vários dicionários flexibiliza a tradução, uma vez que é possível usar os dicionários mais apropriados para o público alvo.

A Figura 1 apresenta a estrutura funcional do MVLIBRAS, onde podemos identificar como é feita a tradução de textos escritos em Português para uma sequência de vídeos.

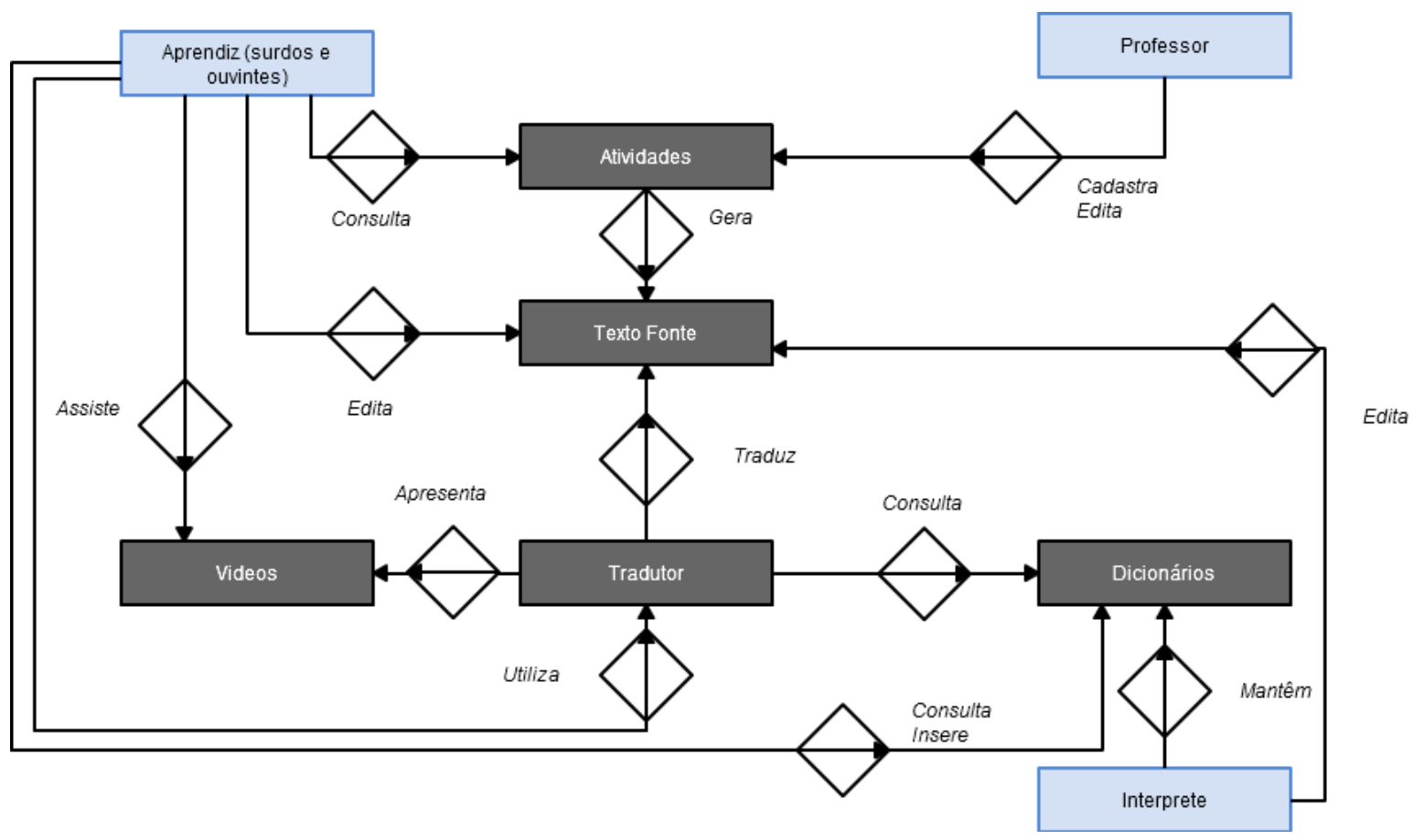

Figura 1. Estrutura Funcional do sistema 
Os aprendizes, professores e intérpretes são os usuários do sistema. Eles usam o sistema para realizar atividades, traduzir seus textos e obter palavras gesticuladas em LIBRAS. O módulo tradutor recebe um texto fonte versionado, escrito em Português, proveniente da edição individual/colaborativa de textos.

O tradutor então consulta os dicionários disponíveis para a tradução do texto e devolve uma sequência de vídeos das palavras LIBRAS correspondentes. Todas as palavras que compõem o texto fonte passam a ser interativas, permitindo a visualização de sua tradução para LIBRAS, em tempo real.

A Figura 2 exibe a arquitetura do sistema. A interação é realizada via browser, facilitando o acesso de seus usuários, uma vez que o sistema não requer instalação, apenas conexão com um servidor contendo o MVLIBRAS. A autenticação de cada usuário libera os recursos digitais correspondentes ao seu perfil.

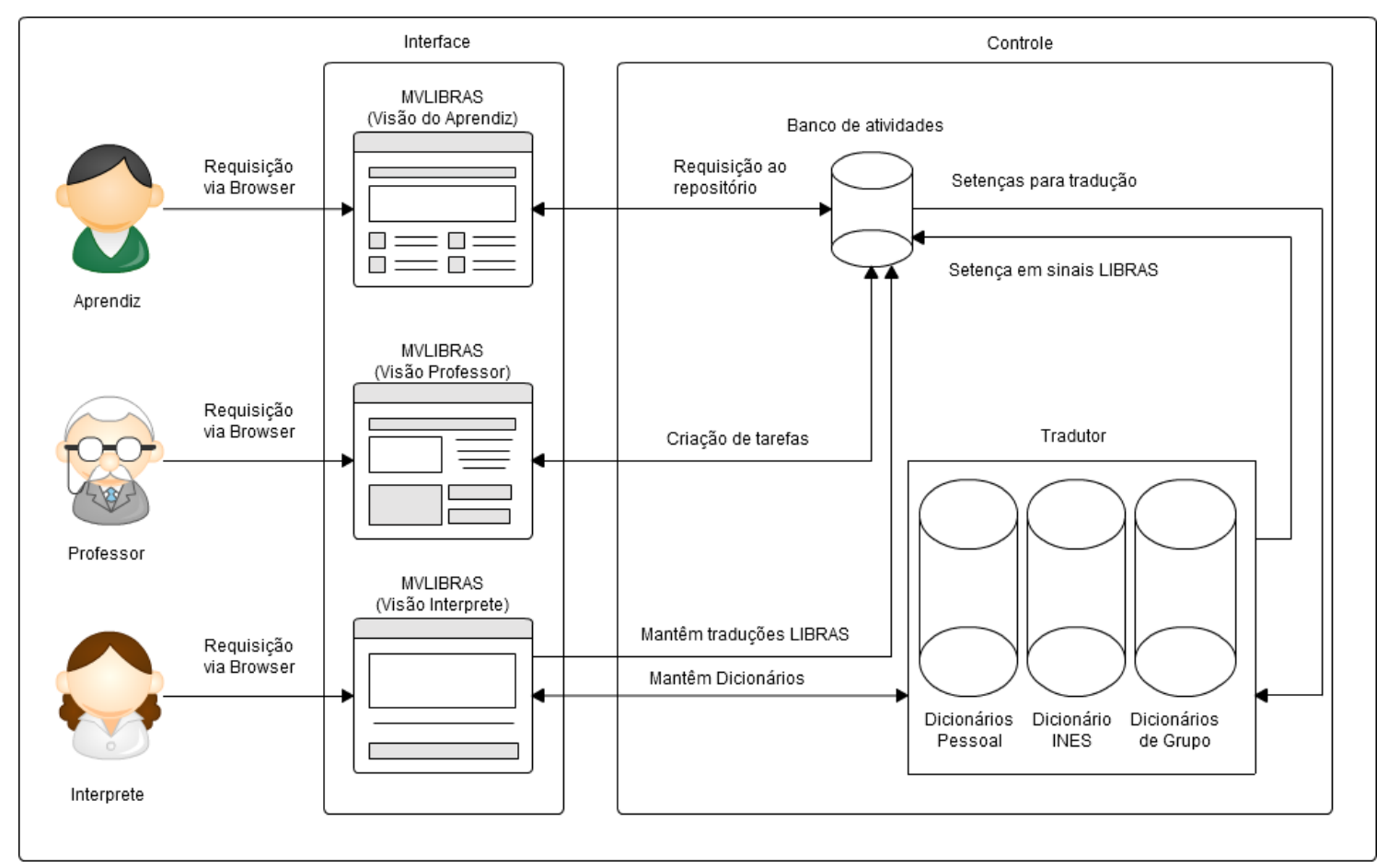

Figura 2. Arquitetura do sistema

O tradutor, como mencionado, recebe uma sentença escrita em Português e devolve uma sequência de sinais LIBRAS, em vídeos. A arquitetura do tradutor possui diversos dicionários de tradução que podem ser expandidos. Entre eles, existe um dicionário padrão do INES [INES 2015], com cerca de 1300 vídeos de palavras LIBRAS. Além do dicionário INES, o intérprete avalia os novos sinais inseridos pelos alunos e, quando aprovados, são armazenados no dicionário pessoal do aprendiz.

O dicionário pessoal é particular de seu criador e visto apenas por ele e por um intérprete autorizado que auxilia no aperfeiçoamento da gesticulação e da execução LIBRAS. Durante essa avaliação dos novos sinais, o intérprete encontra sinais que são usados por um indivíduo que não se encontram no dicionário padrão. Tais palavras após identificadas e revisadas, podem ser adicionadas em um dicionário de grupo, para ficarem visíveis a todo um grupo/turma. 
CBIE-LACLO 2015

Anais do XXVI Simpósio Brasileiro de Informática na Educação (SBIE 2015)

A Figura 3 apresenta a tela do professor, usada para criação/acompanhamento de atividades de edição colaborativa de textos. O professor pode criar a atividade e publicála para edição dos alunos que pertençam a uma turma.

Quando um texto é alterado por um aluno, o sistema salva uma nova versão. Dessa forma, se for necessário o professor pode retornar o texto para uma versão anterior.

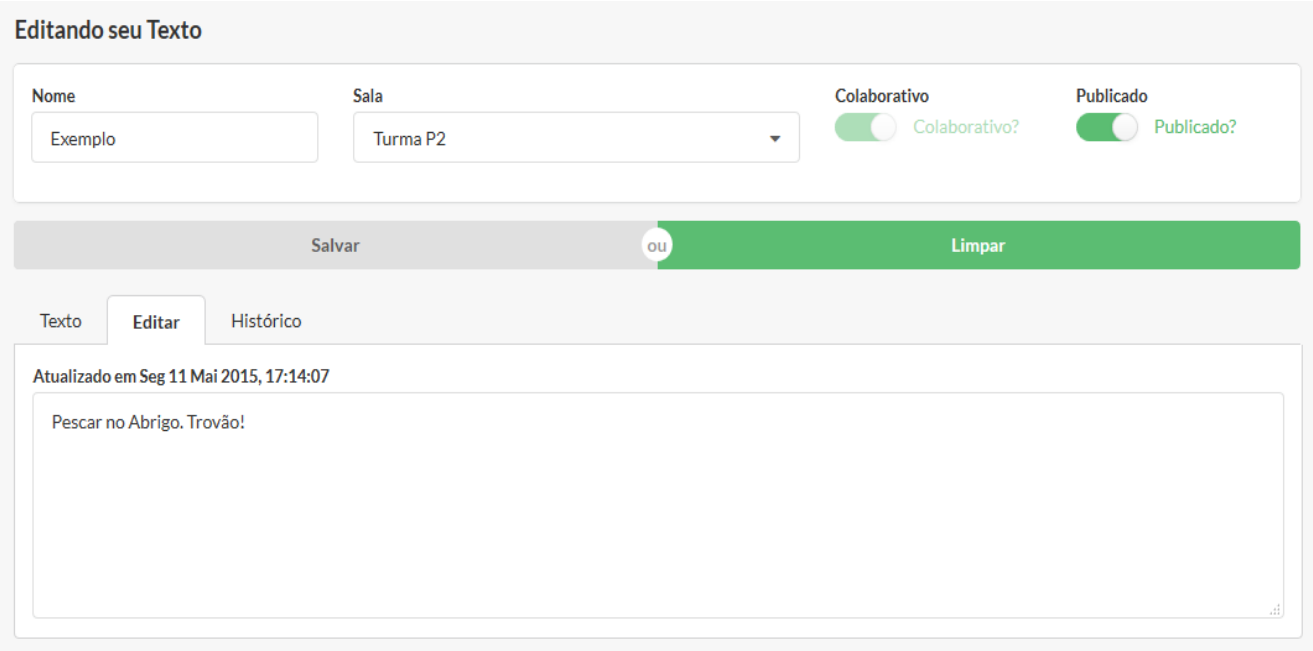

Figura 3. Tela da edição colaborativa do MVLIBRAS

O tradutor recebe o texto resultante de uma atividade colaborativa. A Figura 4 exibe o texto 'Pescar no Abrigo. Trovão!', que será traduzido para LIBRAS, para que o usuário possa ver a gesticulação animada.

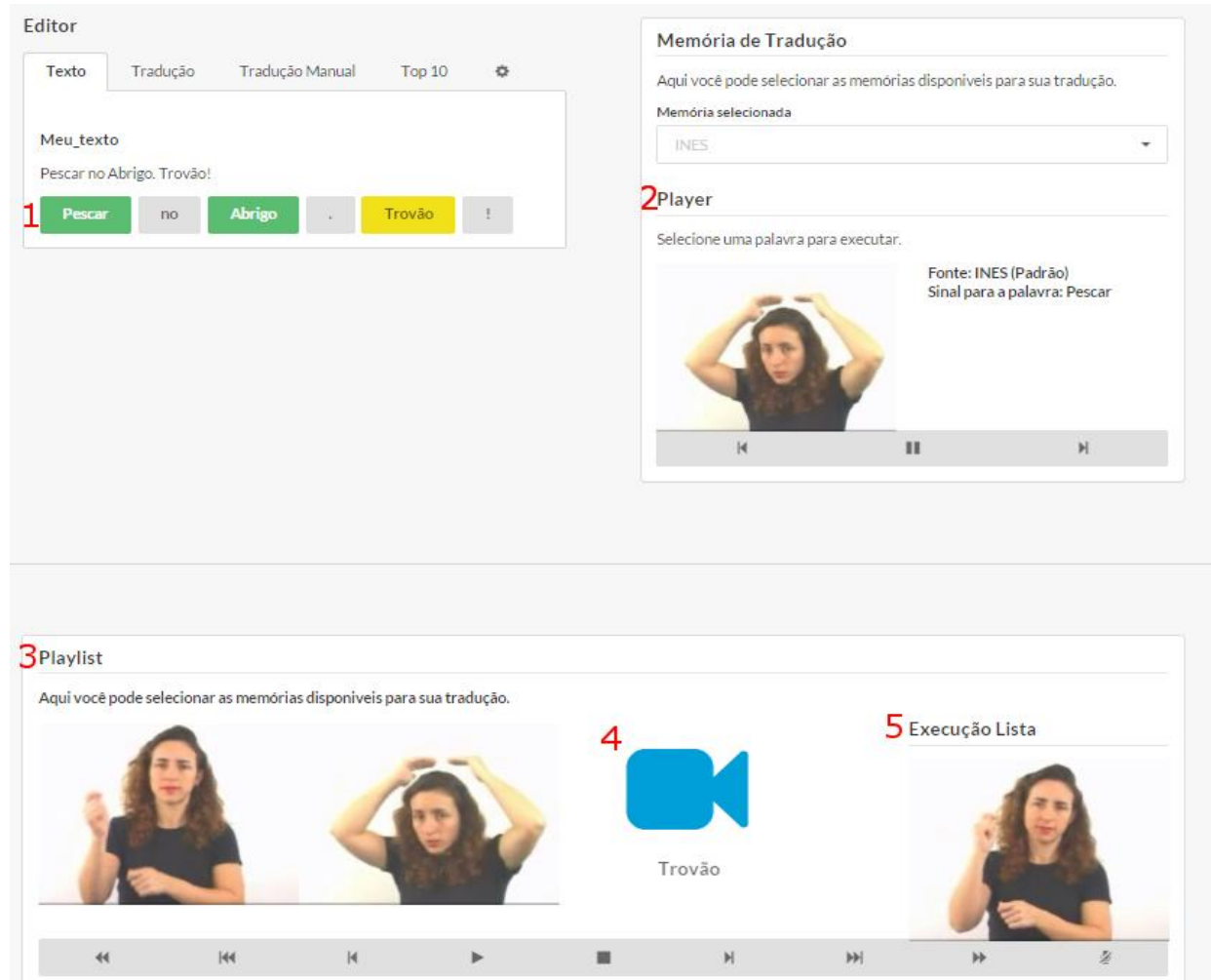

Figura 4. Sistema de tradução em tempo real 
O usuário pode selecionar uma palavra do texto com o clique (1). Se essa palavra for encontrada em um dos dicionários, ela é tarjada de verde e sua tradução para a forma gestual animada é apresentada, na área nomeada 'Player' (2). Na área chamada 'Playlist' (3), é apresentada a tradução completa da sentença. Essa tradução pode ser montada e adaptada pelo intérprete, que pode remover e alterar os vídeos que compõem o conjunto de tradução. Para os testes do tradutor, colocamos uma palavra inexistente nos dicionários ativos, 'Trovão', que fica em amarelo por não ter sido encontrada. $\mathrm{O}$ sistema então sugere ao aprendiz/usuário gravar um vídeo, com a gesticulação dessa palavra, para completar a tradução. Basta o aluno clicar na câmera azul (4).

Após o envio de uma nova palavra LIBRAS, gesticulada e gravada em vídeo, ela fica acessível imediatamente ao usuário, no dicionário pessoal, e aparece em seguida na Playlist. Com a análise e aprovação dos intérpretes, essa nova palavra Libras pode se tornar pública aos grupos existentes e ficar disponível para as próximas traduções.

Após a tradução da sentença, os usuários podem assistir a sequência que é executada na área chamada 'Execução Lista' (5).

\section{Avaliação do sistema}

Os recursos do MVLIBRAS descritos foram usados, durante a realização de atividades da arquitetura pedagógica APPL, por 25 alunos, 3 intérprete e 3 pedagogos, em um curso para profissionais da educação, provido por uma instituição de educação especial. Neste caso, a atividade proposta foi editar colaborativamente palavras relativas ao tema 'Cores'. Assim, cada aluno editou cores que foram adicionadas a um texto a ser traduzido. Outra atividade foi a tradução dessas palavras para LIBRAS, com o uso do tradutor de palavras. Enquanto editavam as palavras relativas às cores, os aprendizes ativavam o tradutor digital de palavras para verem a gesticulação animada das palavras, em LIBRAS, das cores referenciadas pelas palavras escritas por eles em Português.

Após o uso do MVLIBRAS nas atividades pedagógicas, foi realizada uma avaliação da percepção do aprendiz quanto à utilidade dos recursos usados para a edição e tradução (colaborativas) de palavras, bem como o editor de palavras LIBRAS, usado para incluir vídeos, no dicionário LIBRAS usado pelo aprendiz, relativos a palavras LIBRAS que não estavam disponíveis. A totalidade da turma conseguiu realizar a atividade e utilizar a ferramenta. O registro de novos sinais no dicionário pessoal, com a avaliação dos intérpretes, funcionou corretamente e foi aprovada por seus utilizadores. Ficou clara a importância desse mecanismo de registro individual de novos sinais LIBRAS, muito difícil de ser feito sem recurso digital e individualmente em sala.

\section{Considerações Finais}

Os alunos surdos e ouvintes, professores e intérpretes podem usar o MVLIBRAS para o desenvolvimento de atividades pedagógicas de construção colaborativa de textos escritos em Português e a tradução deles para LIBRAS, na forma gestual animada. Assim, várias arquiteturas pedagógicas podem ser projetadas pelos professores com $\mathrm{o}$ uso desse ambiente.

Neste artigo apresentamos uma arquitetura pedagógica que explora a aprendizagem de Português e LIBRAS, em uma comunidade de aprendizes surdos e ouvintes, com o uso de dicionários de tradução de palavras do Português para LIBRAS. 
Algumas das palavras da LIBRAS, na forma gestual animada, usadas nas atividades relatadas, foram editadas pelos próprios aprendizes, sob a supervisão de intérpretes, com recursos do próprio MVLIBRAS. Mesmo recursos digitais simples se constituem em inovações importantes para as comunidades de aprendizes inclusivas e contribuem efetivamente para a aprendizagem de Português e LIBRAS, como foi comprovado durante os experimentos relatados.

A possibilidade de construção dos dicionários pessoais permite ao aprendiz surdo registrar os sinais particulares que usa para se comunicar em LIBRAS. Os sinais não oficiais de LIBRAS, mas compartilhados por outros aprendizes, podem assim ser identificados e usados pela comunidade.

Além dos recursos usados nas traduções de palavras, o MVLIBRAS dispõe de tradutor de sentenças de Português para LIBRAS. Esse tradutor será usado em novas arquiteturas pedagógicas a serem avaliadas em futuros trabalhos.

\section{Agradecimentos}

Esta pesquisa foi patrocinada pela Fundação de Amparo à Pesquisa do Espírito Santo (FAPES) e pela Universidade Federal do Espírito Santo (UFES).

\section{Referências}

Bispo, I. and T. M. Saretto (2015) "Libras no Ensino a Distância no IFPR Ead" In: $1^{s t}$ International Workshop on Assistive Technology, Vitória, Anais $1^{\text {st }}$ International Workshop on Assistive Technology. Vitória: Editora UFES. p. 185-187.

Bistol, C. A., Valentini, C. B. and Simioni, J. L. (2010) "Estudantes Surdos no Ensino Superior: reflexões sobre Inclusão" In: Caderno de Pesquisas, v.40, n. 139, p. 147172.

Brasil (2002) "Código Civil: Dispõe sobre a Língua Brasileira de Sinais - Libras e dá outras providências", http://www.planalto.gov.br/ccivil_03/leis/2002/110436.htm, Abril.

Brasil (2004) "O tradutor e intérprete de língua brasileira de sinais e língua portuguesa", http://portal.mec.gov.br/seesp/arquivos/pdf/tradutorlibras.pdf. Abril.

Brasil (2010) "Código Civil: Regulamenta a profissão de Tradutor e Intérprete da Língua Brasileira de Sinais http://www.planalto.gov.br/ccivil_03/_Ato2007-2010/2010/Lei/L12319.htm. Abril.

Brasil (2012) "Cartilha do Censo 2010: Pessoas com deficiência”, Brasília:SDHPR/SNPD, 2012, 32p.

Breda, W. L. (2008) "Um ambiente para apoio à tradução baseado em conhecimento: estudo de caso com português-libras", Vitória, Universidade Federal do Espírito Santo, $187 \mathrm{p}$.

Carvalho, M. J. S., Nevado, R. A., and Menezes, C. S. (2005) "Arquiteturas Pedagógicas para Educação a Distância: Concepções e Suporte Telemático", In: XVI Simpósio Brasileiro de Informática na Educação, Juiz de Fora-MG. Brasil. pages 351-360. 
Coradine, L. C., Albuquerque, F. C., Silva, Brito, P. H. S., Ferreira, A., Madeiro, J. M. and Perreira, M. C. (2004) "Sistema Falibras: Tradutor do Português (falado ou escrito) para Libras (gestual e animada)", In: XXI Simpósio Brasileiro de telecomunicações.

Costa, E. B., Almeida, H. O., Oliveira, D., Ferneda, E., Barbosa, J. E. L., Nunes R. and Figueredo, T. N. (2004) "Um Ambiente Virtual de Aprendizagem na Web para Apoiar o Ensino da Linguagem Brasileira de Sinais - LIBRAS”, Revista Digital da CVA, v.2, n. 6, mar. 2004.

Farjado, I., Araujo, R. M. E., Krieger, M. and Porta, S. L. (2015) "Mapeamento Estruturado de LIBRAS para utilização em sistemas de comunicação" In: $1^{\text {st }}$ International Workshop on Assistive Technology, Vitória, Anais $1^{\text {st }}$ International Workshop on Assistive Technology. Vitória: Editora UFES. p. 188-191.

INES (2015) "Instituto Nacional de Educação de Surdos", http://www.ines.gov.br/, Abril.

Pimentel, M. e Fuks, H. (2012) "Sistemas Colaborativos", Rio de Janeiro: Elseiver, $451 p$.

Rossi, D., Souza, V. C. and Silva Pinto, S. C. C. (2004) "Sign WebForum: um fórum de Discussão que Utiliza a Troca de Mensagens em Libras na Web", In: XV Simpósio Brasileiro de Informática na Educação, Manaus-AM. Brasil. pages 259-268.

Santarosa, L. M. C., Vieira, Maristela C., Correa, Y. and Biazus, M. C. (2014) "Para além da interação: o papel de aplicativos como ProDeaf e HandTalk na constituição do sujeito surdo" In: Seminário Nacional de Inclusão Digital, Passo Fundo. Anais III SENID - $3^{\circ}$ Seminário Nacional de Inclusão Digital. Passo Fundo: Editora UPF.

Souza, M. B., Rocha, P. M., Sá, A. B. and Uchoa, S. A. C. (2013) "Trabalho em equipe na atenção primária: a experiência de Portugal”, Rev Panam Salud Publica, v.33, n.3, p. 190-195.

Souza, V. C. and Silva Pinto, S. C. C. (2003) "Sign WebMessage: uma ferramenta para comunicação via web através da Língua Brasileira de Sinais - Libras", In: XIV Simpósio Brasileiro de Informática na Educação, Rio de Janeiro-RJ. Brasil. pages 395-404.

Souza, V. C. and Silva Pinto, S. C. C. (2004) "O Aprimoramento do Sign WebMessage como Base para o Desenvolvimento da SWService: uma Biblioteca para a Escrita da Libras na Internet Baseada em Web Services", In: XV Simpósio Brasileiro de Informática na Educação, Manaus-AM. Brasil. pages 248-258. 